\title{
Efeito da Profundidade de Soldagem no Hidrogênio Difusível de Soldas Molhadas
}

\author{
(Effect of Water Depth on Diffusible Hydrogen on Wet Welds)
}

\author{
Weslley Carlos Dias da Silva ${ }^{1}$, Alexandre Queiroz Bracarense ${ }^{1}$, Ezequiel Caires Pereira Pessoa ${ }^{2}$ \\ ${ }^{1}$ Universidade Federal de Minas Gerais, Departamento de Engenharia Mecânica/Laboratório de Robótica de Soldagem e Simulação, \\ Belo Horizonte, Minas Gerais,Brasil,weslleycds@yahoo.com.br,bracarense@ufmg.br \\ ${ }^{2}$ Instituto Federal de Minas Gerais, Betim, Minas Gerais, Brasil, ecpp76@gmail.com
}

\begin{abstract}
Resumo
Em soldagem subaquática molhada, a ocorrência de poros e trincas a frio pode ter um efeito bastante prejudicial nas propriedades mecânicas da junta soldada. O hidrogênio contribui diretamente para o aparecimento destas duas descontinuidades. A quantidade de hidrogênio difusível (Hdif) no metal de solda pode ser influenciada por diversos fatores. Todavia, pouco se sabe sobre a influência da profundidade de soldagem (pressão) sobre a quantidade de Hdif no metal de solda. Neste trabalho, diversas medições de hidrogênio difusivel foram feitas nas profundidades de $0,30 \mathrm{~m}, 10 \mathrm{~m}$ e $20 \mathrm{~m}$ e $30 \mathrm{~m}$ em soldagem molhada. O consumível utilizado foi o eletrodo comercial E6013 envernizado. As medições de hidrogênio difusível foram feitas através do método da cromatografia. Para medição de porosidade foi utilizado o método macrográfico e um programa analisador de imagem. O hidrogênio residual também foi medido. Os resultados mostraram que o hidrogênio difusível reduziu significativamente com o aumento da pressão hidrostática ao contrário da porosidade, que aumentou com o aumento da pressão hidrostática. Não se observou alterações apreciáveis no hidrogênio residual do metal de solda. Desta forma, é possível concluir que a profundidade de soldagem afeta diversos aspectos da soldagem subaquática molhada, em especial, o hidrogênio difusível e porosidade, conforme foi observado neste trabalho.
\end{abstract}

Palavras-chave: Soldagem Subaquática Molhada; Hidrogênio Difusível; Pressão Hidrostática.

Abstract: In underwater wet welding, cold cracking and pores might have a deleterious effect in the mechanical properties of welded joint. The hydrogen might act in the occurrence of theses discontinuities. The amount of diffusible hydrogen in the weld metal can be influenced by several factors. However, not yet known whether the depth of welding (pressure) affects the amount of diffusible hydrogen in weld metal. In this work, several measurements of diffusible hydrogen were made at following depth: $0.30 \mathrm{~m}, 10 \mathrm{~m}$, $20 \mathrm{~m}$ and $30 \mathrm{~m}$ at wet welding. The electrode used was commercial waterproofed E6013. The diffusible hydrogen measurements were made through the gas chromatography method following the AWS D3.6M procedure. The porosity was measured using the macrographic method and an image analyser program. The residual hydrogen also was measured. The results showed that diffusible hydrogen reduced substantially as the hydrostatic pressure increased. The porosity increased as the hydrostatic pressure increased. It was not observed changes in the residual hydrogen of the weld metal. So, it is possible to conclude that the welding depth affects several aspects of the underwater wet welding, in special, the diffusible hydrogen and porosity.

Key-words: Underwater Wet Welding; Diffusible Hydrogen; Hydrostatic Pressure.

\section{Introdução}

O trincamento por hidrogênio é o defeito metalúrgico mais recorrente na soldagem de aços ferríticos [1]. O mecanismo pelo qual ocorre a fissuração a frio ainda não é bem conhecido [2], embora várias teorias tenham sido propostas. Troiano (1960) [3] propôs que o hidrogênio promove o crescimento da trinca pela redução das forças coesivas do material. Petch (1952) [4]

(Recebido em 26/01/2012; Texto final em 21/05/2012). propôs que o hidrogênio promove o crescimento da fissura pela redução da energia superficial da trinca. Beachem (1972) [5] propôs que o hidrogênio auxilia na deformação microscópica a frente da ponta da trinca. Savage et al. (1976) [6] explicou o trincamento por hidrogênio no metal de solda baseado na teoria de Troiano. Gedeon e Eagar (1990) [7] reportaram que o seu resultado fundamentou e ampliou a teoria de Beachem. Bailey et al (1993) [1] reportou que uma possível hipótese para a fissuração a frio é que os átomos de hidrogênio que ficam dissolvidos intersticialmente na matriz ferrítica interferem no movimento das discordâncias (discordâncias são imperfeições na estrutura cristalina que permitem a deformação plástica). Como a velocidade de difusão do hidrogênio no aço reduz com a temperatura, os átomos de hidrogênio podem se mover na correta velocidade para interagir com as discordâncias dentro 

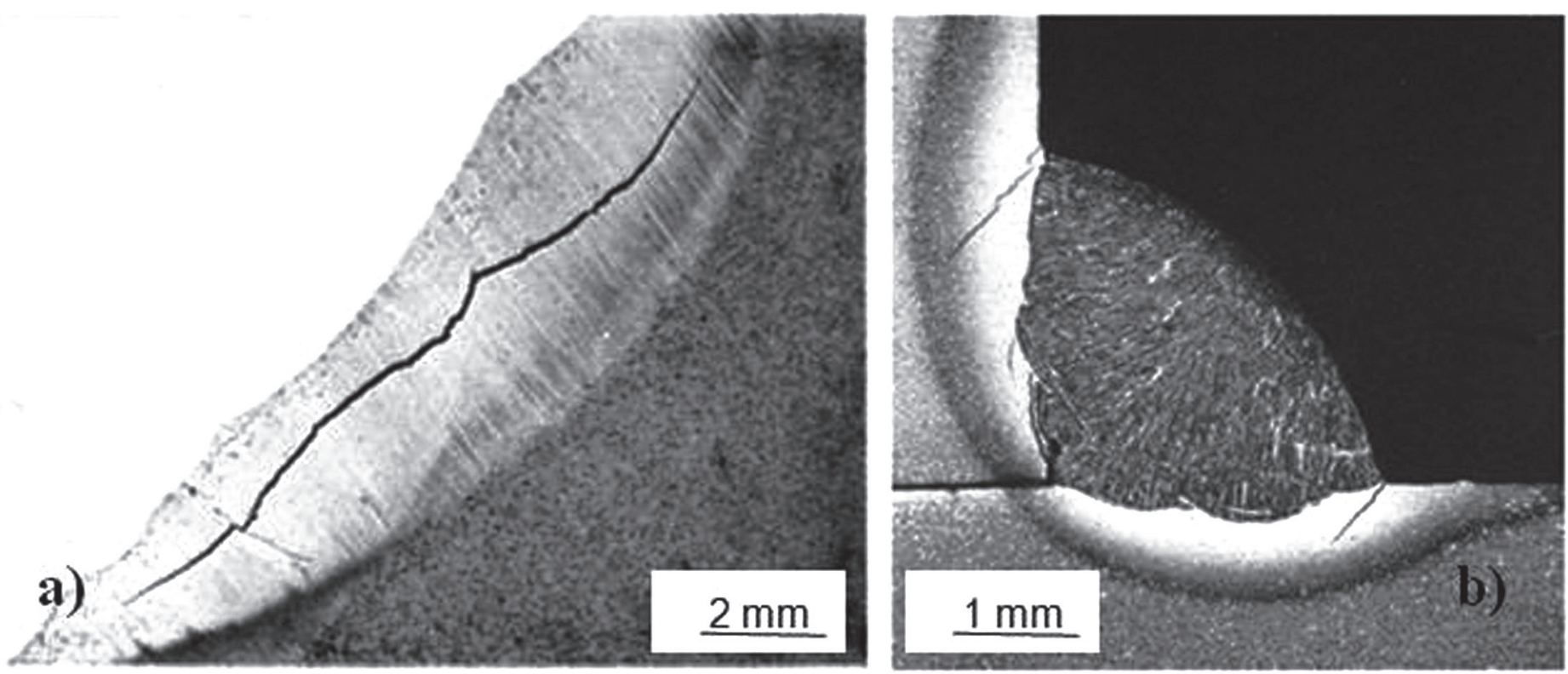

Figura 1. a) Trincamento sob cordão na ZTA em um aço baixa-liga com ampliação de 8 vezes e b) Fissuração a frio em solda de filete em um aço 1040 com ampliação de 4,5 vezes adaptado de [2]

de uma faixa limitada de temperatura entre 100 e $200^{\circ} \mathrm{C}$ acima e abaixo da temperatura ambiente. Além disso, a interferência somente ocorre quando o aço é deformado em baixas taxas de deformação. Na Figura 1 pode-se observar o aspecto das trincas por hidrogênio na ZTA em diferentes situações.

As trincas por hidrogênio são causadas por quatro fatores [8]:

- Hidrogênio no metal de solda;

- Altas tensões;

- Microestrutura suscetível (martensita);

- Relativa baixa temperatura (entre -100 a $200{ }^{\circ} \mathrm{C}$ ).

De forma geral, estas quatro condições citadas anteriormente são facilmente encontradas em soldagem subaquática molhada. Primeiramente, deve-se ressaltar que durante a execução das soldas molhadas, grandes quantidades de hidrogênio podem entrar na atmosfera do arco e, em seqüência na poça de fusão, oriundos da quebra da molécula de água em contato com o arco elétrico. Geralmente, os eletrodos revestidos utilizados em soldagem subaquática molhada são previamente ressecados e envernizados, ou recebe qualquer outro tipo de proteção, para evitar que o revestimento seja contaminado pela água na vizinhança do eletrodo.

As tensões residuais são desenvolvidas devido à contração térmica no resfriamento da solda. O nível de tensão residual está diretamente ligado ao grau de restrição da junta soldada. A tensão residual é função das dimensões da solda, da geometria da junta, restrições externas e limites de escoamento do metal de solda e metal de base. De forma geral, para uma dada microestrutura, quanto maior for o nível de tensões residuais na junta soldada, maiores serão as chances de aparecimento de trincas na ZTA e metal de solda [9].

Com relação à microestrutura, é reportado na literatura ([2], [8] e [9]) que a formação de microconstituintes mais duros na ZTA e metal de solda são mais propensos ao aparecimento de trincas a frio. A microestrutura do metal de solda e da ZTA depende da taxa de resfriamento na faixa de temperatura crítica do aço, composição química e temperabilidade do aço [9]. A taxa de resfriamento depende do aporte térmico, temperatura da junta antes da soldagem, espessura da chapa e geometria da junta.

A temperatura é também uma variável importante no tocante à fissuração a frio. A taxa de difusão do hidrogênio em aços ferríticos diminui consideravelmente a partir de temperaturas menores que $150^{\circ} \mathrm{C}$. Em temperaturas acima de $150^{\circ} \mathrm{C}$, a difusividade do hidrogênio é favorecida no metal de solda e ZTA. De forma geral, os métodos conhecidos para redução das trincas a frio buscam reduzir a quantidade de hidrogênio absorvida pela poça de fusão e permitir que o hidrogênio presente no metal de solda e ZTA escape antes que a junta soldada atinja temperaturas próximas da temperatura ambiente [9].

Durante a soldagem, hidrogênio é absorvido da atmosfera do arco pela poça de fusão. Durante o resfriamento, grande parte deste hidrogênio escapa do cordão solidificado por difusão, mas parte dele se difunde para a ZTA e metal de base. Conforme o metal de solda passa por transformação de austenita para perlita (ferrita e cementita), o hidrogênio é rejeitado para a vizinhança devido à menor solubilidade do hidrogênio em ferrita do que em austenita. Geralmente, o metal de solda tem um teor de carbono mais baixo que o metal de base, pois usualmente o teor de carbono do metal de adição é menor do que o teor de carbono do metal de base. Assim, é provável que a transformação da austenita em perlita ocorra primeiro no metal de solda que a transformação de austenita em martensita na ZTA. O coeficiente de difusão de hidrogênio em materiais ferríticos é maior do que em materiais austeníticos. $\mathrm{O}$ alto coeficiente de difusão do hidrogênio em aços ferríticos favorece o processo de difusão do hidrogênio. Por outro lado, o menor coeficiente de difusão do hidrogênio na austenita dificulta a difusão do hidrogênio da ZTA 
para o metal de base antes da transformação da austenita em martensita. Esta combinação de hidrogênio com martensita na ZTA promove o trincamento por hidrogênio [2]. Na Figura 2 é apresentado um modelo que ilustra a difusão do hidrogênio do metal de solda para a ZTA [2]. A linha TF representa a fronteira de transformação da austenita para perlita no metal de solda, e a linha TB representa a linha de transformação da austenita em martensita na ZTA.

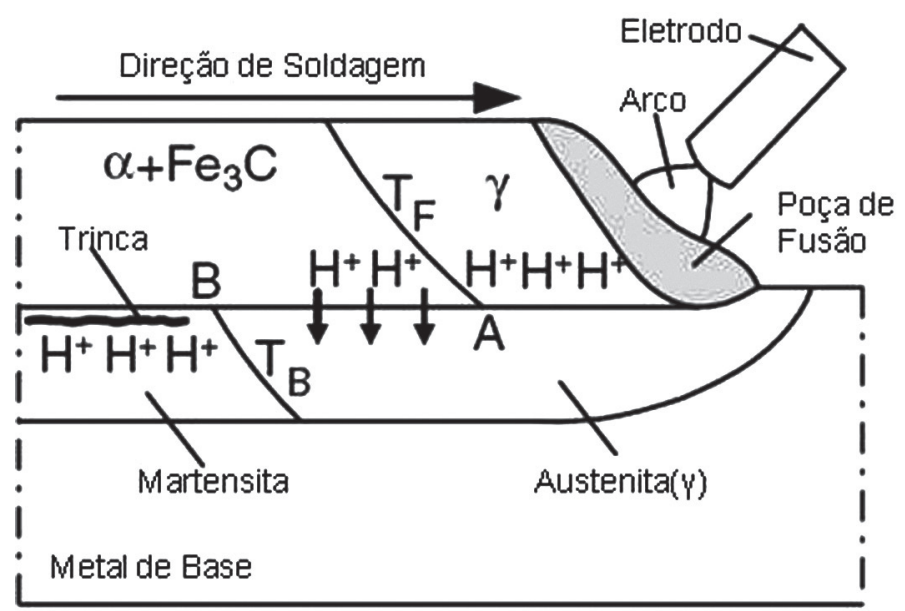

Figura 2. Difusão do hidrogênio do metal de solda para a ZTA durante a soldagem adaptado de [2]

O hidrogênio no metal de solda pode se apresentar em duas formas: hidrogênio difusível e hidrogênio residual. $\mathrm{O}$ hidrogênio difusível se apresenta dissolvido intersticialmente na estrutura cristalina do metal de solda e ZTA na forma iônica $\left(\mathrm{H}^{+}\right)$; e devido ao seu tamanho reduzido, é capaz de se difundir pela estrutura cristalina do metal de solda e ZTA. O hidrogênio residual é a parcela do teor de hidrogênio na qual não pode ser liberada por difusão em temperatura ambiente, mas pode ser extraída em temperaturas mais altas $(\sim 650$

${ }^{\circ} \mathrm{C}$ ). Acredita-se que o hidrogênio residual possa ficar aprisionado na forma molecular, na rede cristalina, em vazios (associado com inclusões não-metálicas) ou em combinação química com outros elementos (o hidrogênio pode se associar com carbono formando o gás metano) [1].

A profundidade em que são feitas as soldas molhadas influencia diversos parâmetros. Ando e Asahina (1983) [10] estudaram a relação entre a pressão hidrostática e o teor de hidrogênio difusível das juntas soldadas. Diferentes famílias de eletrodos foram utilizadas (D4327-eletrodo com óxido de ferro e pó de ferro, D4324-rutílico, D4340-ilmenítico, D4326-eletrodo de baixo de hidrogênio, D308-austenítico e D310-austenítico). Conforme pode ser observado na Figura 3, o hidrogênio difusível apresenta o maior valor na pressão de $0,30 \mathrm{~m}$ e depois decresce com o aumento da pressão hidrostática. Comparativamente, as soldas produzidas na profundidade de $0,30 \mathrm{~m}$ apresentaram uma quantidade de hidrogênio significativamente maior do que as soldas produzidas ao ar. Nesse trabalho, Ando e Asahina (1983) [10] não explicaram porque o hidrogênio difusível apresentou tendência de diminuição com a pressão.

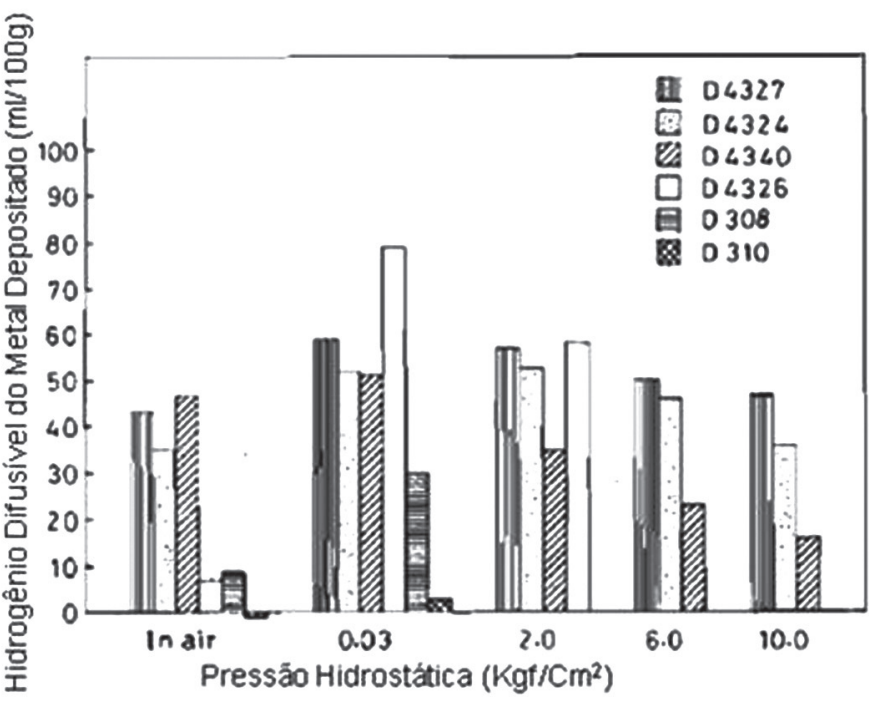

Figura 3. Relação entre pressão e hidrogênio difusível dos metais depositados adaptado de [10]

Neste trabalho será possível traçar um paralelo entre os resultados obtidos e as medições feitas por Ando e Asahina (1983) [10], além de apresentar uma possível explicação para o comportamento do hidrogênio difusível com a pressão. Assim sendo, a grande motivação desta investigação é entender o comportamento do hidrogênio difusível com a pressão hidrostática, além de fazer a devida quantificação do hidrogênio (difusível e residual) para diferentes profundidades. Uma vez que as formulações dos eletrodos revestidos são feitas para dados obtidos em profundidades inferiores a $0,5 \mathrm{~m}$, tem-se um grande valor técnico-científico saber, para um dado consumível, qual valor de hidrogênio difusível do metal de solda produzido pelo mesmo em diferentes profundidades de soldagem.

\section{Materiais e Métodos}

Para execução das soldas molhadas, utilizou-se um sistema de soldagem por gravidade dentro de um vaso de pressão especialmente preparado para soldagem subaquática e remoção dos corpos de prova para medição do hidrogênio difusível. $\mathrm{O}$ ângulo entre o eletrodo e a chapa foi mantido fixo em $60^{\circ}$. Este ângulo está diretamente ligado com a velocidade de soldagem. Como se utilizou um sistema de soldagem por gravidade, a execução dos cordões de solda ocorreu por arraste do eletrodo.

Na Figura 4 pode-se ver o vaso de pressão especialmente preparado para soldagem subaquática com escotilha adaptada para remoção de corpos de prova para ensaio de hidrogênio difusível. Seguiu-se o procedimento normalizado, mantendo o tempo de 2 minutos entre o fim da soldagem e a colocação do corpo de prova no dispositivo de coleta de hidrogênio. Em relação à polaridade de soldagem, trabalhou-se em polaridade direta (DCEN), sendo a corrente de soldagem mantida constante no valor de $170 \mathrm{~A}$ em todos os testes realizados. 


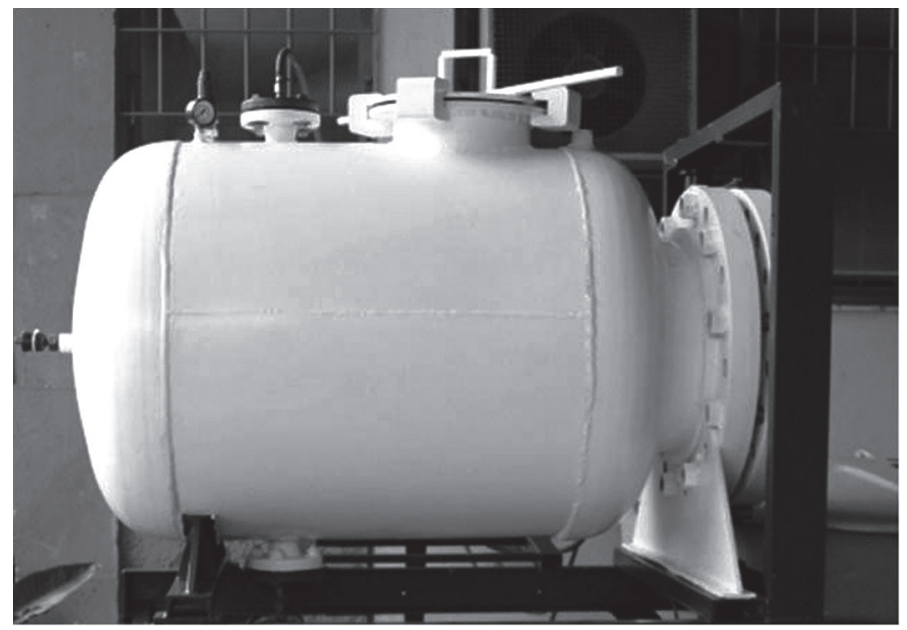

Figura 4. Vaso de pressão especialmente preparado para soldagem subaquática com escotilha adaptada para remoção de corpos de prova para ensaio de hidrogênio difusível

A deposição dos cordões de solda foi feita utilizando eletrodos rutílicos E6013 com 3,25 mm de diâmetro. Os eletrodos foram ressecados e envernizados com verniz vinílico. Foram utilizadas peças de aço ASTM A36 como metal de base. Primeiramente, foram feitos quatro cordões de solda em condições de pressão correspondentes as profundidades de $0,30 \mathrm{~m}, 10 \mathrm{~m}, 20 \mathrm{~m} \mathrm{e}$ $30 \mathrm{~m}$ com o objetivo de comparar o aspecto superficial dos cordões de solda e soldabilidade nas diferentes profundidades. Estas pressões foram escolhidas para que se pudesse entender a relação do hidrogênio difusível nas profundidades onde a soldagem subaquática molhada por eletrodo revestido é mais utilizada na costa brasileira. A cromatografia gasosa foi o método utilizado para medição do hidrogênio difusível, utilizando como referência a norma ASTM E260-96 [11]. Em cada profundidade foram obtidos pelo menos 12 resultados de hidrogênio difusível.

Prosseguindo-se os experimentos, mediu-se a porosidade do metal de solda dos cordões produzidos. As amostras para medição da porosidade foram obtidas dos corpos-de-prova utilizados para medição do hidrogênio difusível. Assim, para cada profundidade, pelo menos 12 amostras foram utilizadas. As amostras foram embutidas e devidamente preparadas com lixas nas granulações 100, 220, 440, 600 e 1200. Após isto, as amostras foram devidamente fotografadas para posterior mensuração da área dos poros em um programa analisador de imagem. Para se conhecer a área do metal de solda, as amostras foram atacadas por uma solução de Nital 10\% (solução com $10 \%$ de ácido nítrico e 90\% de álcool 99,3INPM) e fotografadas por meio de uma lupa com aumento de 10 vezes. Novamente o programa analisador de imagem foi utilizado para medição da área do metal de solda. Por fim, a porosidade do metal de solda foi calculada pela Equação 1.

\section{Porosidade $=\frac{\text { Área total dos poros }}{\text { Área do metal de solda }} \times 100 \%$}

Realizou-se também a medição do hidrogênio residual das soldas molhadas. Para cada profundidade, duas amostras foram escolhidas. O critério de escolha das amostras se baseou no valor do resultado de hidrogênio difusível obtidos anteriormente, sendo escolhidas as amostras cujo valor de hidrogênio difusível mais se aproximou do valor médio dos seus respectivos grupos amostrais. Para medição do hidrogênio residual, utilizouse método de extração a quente por corrente de gás [12]. Este método consiste em aquecer a amostra em temperaturas elevadas o suficiente para que todo o hidrogênio contido na mesma possa sair. Em sequência, este hidrogênio é arrastado por um corrente de gás. Devido à diferença de condutividade térmica da corrente de gás com hidrogênio e da mesma sem hidrogênio (valor padrão), é possível obter o hidrogênio residual da amostra analisada. Por causa de problemas experimentais não foi possível obter os valores de hidrogênio residual a $30 \mathrm{~m}$.

Com relação à morfologia do cordão de solda, alguns parâmetros foram medidos, sendo estes: largura, penetração e reforço do cordão de solda. As amostras utilizadas foram as mesmas que previamente foram utilizadas para medição da porosidade. Estas amostras já tinham sido atacadas quimicamente em Nital 10\% e fotografadas. O programa analisador de imagem foi utilizado para medição da largura, penetração e reforço do cordão de solda. Na Figura 5 é possível visualizar um desenho esquemático com os parâmetros geométricos medidos do cordão de solda.

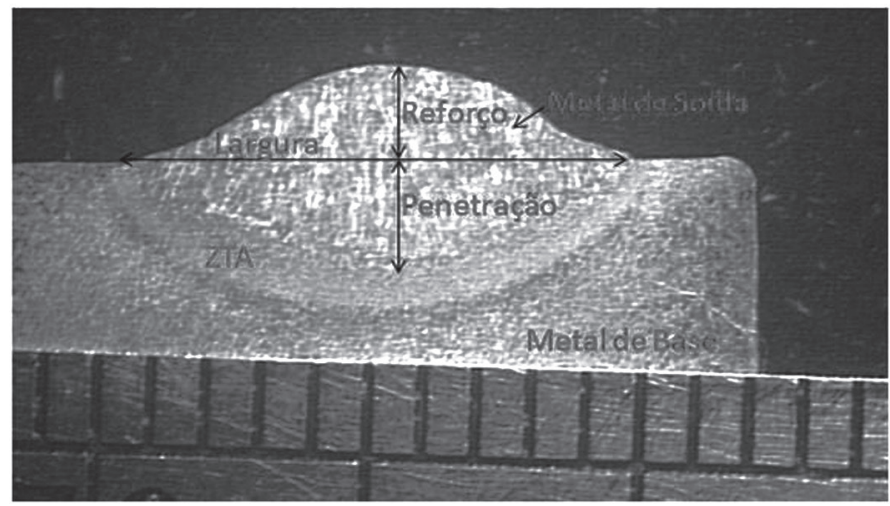

Figura 5. Desenho esquemático ilustrando os parâmetros reforço, penetração e largura do cordão de solda.

Com o intuito de entender os fenômenos de transferência metálica durante a soldagem e para se obter um maior entendimento da estabilidade do arco elétrico com a profundidade, realizou-se a aquisição dos sinais de tensão e corrente de soldagem durante a realização de cordões sobre chapa. Foram feitos quatro cordões de solda, um em cada profundidade. Os parâmetros utilizados foram os mesmos para a medição do hidrogênio difusível, sendo utilizado o mesmo aço (ASTM A36) e eletrodo (E6013), com exceção da geometria da chapa do metal de base. Esta possuía 12,7 mm de espessura, por 100 $\mathrm{mm}$ de largura e $250 \mathrm{~mm}$ de comprimento. A taxa de aquisição de dados foi de $2 \mathrm{kHz}$. A aquisição de dados foi feita em um intervalo de tempo igual a 5 segundos. A aquisição de dados se iniciou em alguns segundos após a abertura do arco elétrico para se evitar o período transiente dos sinais de corrente e tensão. Os dados foram trabalhados em uma planilha de cálculos. A partir dos sinais de tensão, calcularam-se os valores da média e o 
desvio padrão da tensão. O número de curtos-circuitos também foi calculado. Considerou-se como curto-circuito toda vez que a tensão foi inferior a 5 voltz.

\section{Resultados e Discussão}

Na Figura 6, pode-se visualizar os cordões de solda realizados nas quatro profundidades testadas neste presente estudo. Em termos gerais, todos os cordões de solda apresentaram escória com ótima destacabilidade e poucos respingos. A aparência superficial dos cordões de solda pode ser considerada aceitável para soldagem subaquática molhada, com destaque para o cordão de solda realizado a $20 \mathrm{~m}$. Não se detectou poros superficiais nos cordões de solda, com exceção do cordão de solda realizado a 30 $\mathrm{m}$ que apresentou poros na cratera. Isto ocorreu, provavelmente, a uma falha na proteção gasosa do arco elétrico no momento de extinção do mesmo.

A ocorrência de mordeduras só foi observada na profundidade de $0,3 \mathrm{~m}$. Comparativamente, observou-se um aumento na molhabilidade do cordão de solda conforme se aumentou a pressão hidrostática. Com o aumento da profundidade, a pressão hidrostática atuando na poça de fusão líquida tende a espalhá-la no sobre o metal de base, acarretando em um aumento na largura do cordão de solda e redução no reforço, além da já conhecida melhoria da estabilidade do arco elétrico em profundidades acima de 5 metros.

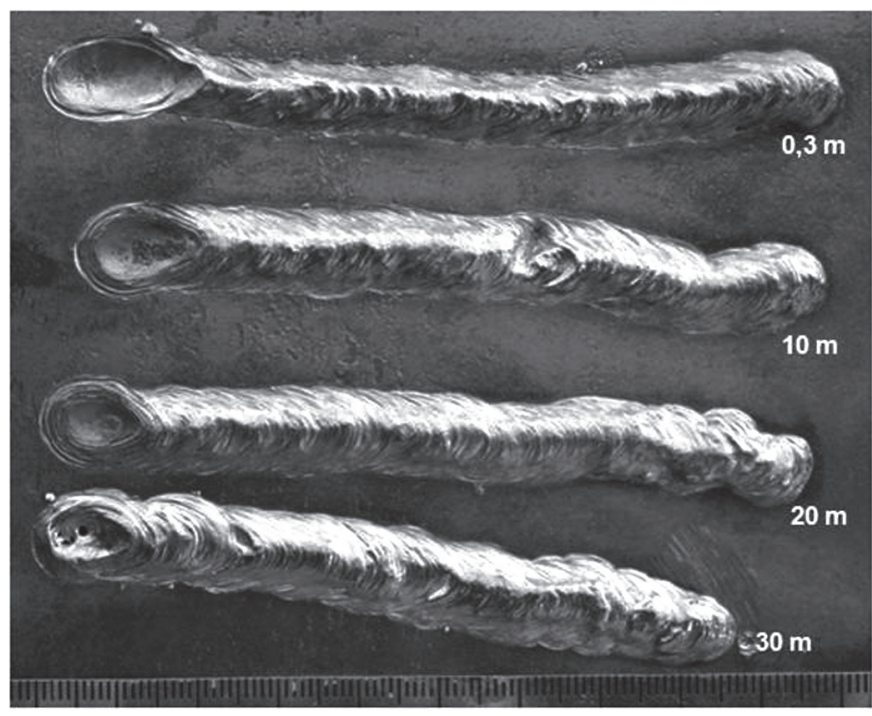

Figura 6. Cordões de solda realizados com o eletrodo E6013, com corrente de soldagem de $170 \mathrm{~A}$, em quatro profundidades diferentes $(0,3 \mathrm{~m}, 10 \mathrm{~m}, 20 \mathrm{~m}$ e $30 \mathrm{~m})$

Conforme foi reportado anteriormente, os sinais de tensão foram adquiridos durante a soldagem dos cordões sobre chapa por um período de 5 segundos. Variando-se a pressão de 0,3 $\mathrm{m}$ para $10 \mathrm{~m}$, a tensão de soldagem reduziu significativamente. A mesma tendência de redução da tensão média de soldagem com o aumento da profundidade ocorreu quando se variou a profundidade de $10 \mathrm{~m}$ para $20 \mathrm{~m}$ e $20 \mathrm{~m}$ para $30 \mathrm{~m}$, porém; de forma menos acentuada. Como as soldas foram feitas por arraste, a redução nos valores de tensão não necessariamente implica em redução do comprimento do arco, exceto quando ocorre uma redução no comprimento do cone do revestimento formado na ponta do eletrodo. Provavelmente, a redução da tensão com a profundidade está ligada ao aumento da instabilidade do arco causado pela perda de potência, que ocorre com o aumento da pressão hidrostática, uma vez que a corrente de soldagem foi a mesma para todas as profundidades. Os resultados referentes à tensão média de soldagem e número de curtos-circuitos estão mostrados na Tabela 1 .

Além da quantificação da tensão média de soldagem, o número de curtos-circuitos foi calculado no intervalo de tempo tomado para amostragem. Para o cordão de solda realizado na profundidade de $0,3 \mathrm{~m}$, não se observou a ocorrência de curtoscircuitos. Contudo, nas demais profundidades foi possível verificar a ocorrência de curtos-circuitos, sendo possível observar a ocorrência de 20 curtos-circuitos em um intervalo de 5 segundos para o cordão de solda realizado a $10 \mathrm{~m}, 13$ curtos-circuitos a $20 \mathrm{~m}$ e 16 curtos-circuitos a $30 \mathrm{~m}$. É natural a ocorrência de curtos-circuitos para as soldas realizadas a $10 \mathrm{~m}$, $20 \mathrm{~m}$ e $30 \mathrm{~m}$ devido aos menores valores de tensão. Assim, as chances da gota líquida tocar a poça de fusão antes mesmo de se destacar do eletrodo, o que caracteriza um curto-circuito, são aumentadas.

Tabela 1. Variação da tensão média de soldagem e número de curtos-circuitos

\begin{tabular}{|c|c|c|}
\hline Profundidade (m) & Tensão Média (V) & $\begin{array}{c}\text { Número de } \\
\text { Curtos-circuitos }\end{array}$ \\
\hline 0,3 & 31 & 0 \\
\hline 10 & 23,2 & 20 \\
\hline 20 & 20,9 & 13 \\
\hline 30 & 19,9 & 16 \\
\hline
\end{tabular}

O hidrogênio difusível do metal de solda depositado foi medido pelo método da cromatografia gasosa nas diversas profundidades estudadas neste trabalho e os resultados podem ser visualizados na Figura 7 com a devida barra de erros (desvio padrão). De forma geral, o hidrogênio difusível reduziu com o aumento da profundidade. Variando-se a profundidade de 0,3 $\mathrm{m}$ para $10 \mathrm{~m}$, o hidrogênio difusível reduziu $25 \%$, seguindo de uma redução de $16 \%$ quando se variou a profundidade de $10 \mathrm{~m}$ para $20 \mathrm{~m}$. É importante ressaltar que estas variações apresentadas foram consideradas com relação ao valor médio. Todavia, os resultados obtidos para a profundidade de $30 \mathrm{~m}$ não foram estatisticamente diferentes dos resultados obtidos na profundidade de $20 \mathrm{~m}$. Isto significa que, provavelmente, o hidrogênio difusível chega em um patamar constante para pressões a partir de $20 \mathrm{~m}$ (estabilização). Este resultado coaduna com o de Ibarra et al (1994) [13], onde foi relatado que o teor de oxigênio no metal de solda aumenta com a pressão hidrostática em soldagem subaquática molhada e posteriormente, alcança um patamar constante. Existe uma relação entre o oxigênio e hidrogênio dissolvido no metal de solda. Esta relação entre estes dois elementos é inversamente proporcional, ou seja; um 
aumento no teor de oxigênio no metal de solda implica em uma redução do hidrogênio dissolvido no metal de solda e vice-versa.

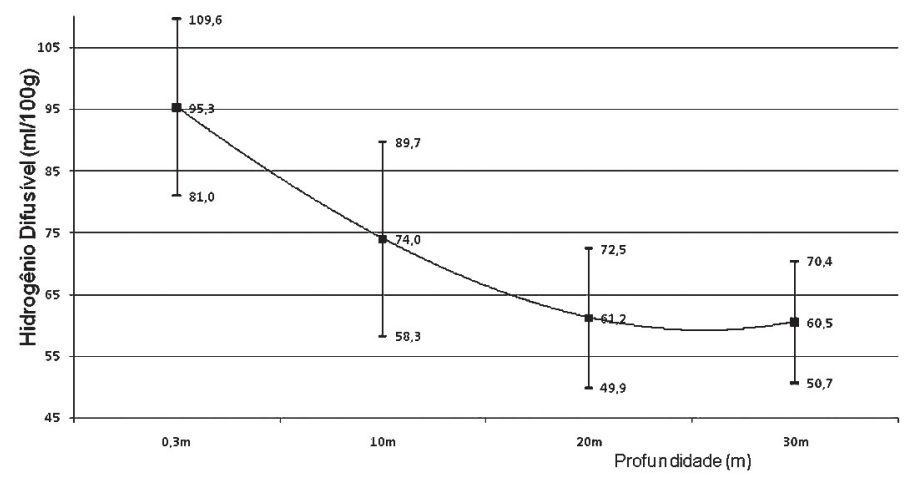

Figura 7. Variação do hidrogênio difusível do metal de solda depositado com a profundidade para o eletrodo E6013

Os resultados obtidos para o hidrogênio difusível do metal de solda depositado foram comparados com os resultados obtidos por Ando e Asahina (1983) [10], conforme pode ser observado na Figura 8. Pode-se observar que Ando e Asahina (1983) [10] não observaram mudanças significativas no hidrogênio difusível com relação ao aumento da profundidade de $0,3 \mathrm{~m}$ para $20 \mathrm{~m}$. Além disto, eles não observaram a estabilização de hidrogênio conforme observado na Figura 8. Uma possível explicação para isto pode ser o fato de os resultados dos dois trabalhos terem sido obtidos por métodos diferentes. Ando e Asahina (1983) [10] usaram o método da glicerina e neste foi usado o método da cromatografia gasosa. Além do mais, outros parâmetros, tais como: diâmetro do eletrodo, corrente de soldagem e configuração do sistema de soldagem por gravidade foram diferentes. Apesar disto, em ambos os trabalhos foi possível observar uma redução no hidrogênio difusível com o aumento da profundidade, o que pode indicar claramente uma tendência de comportamento entre estas duas variáveis.

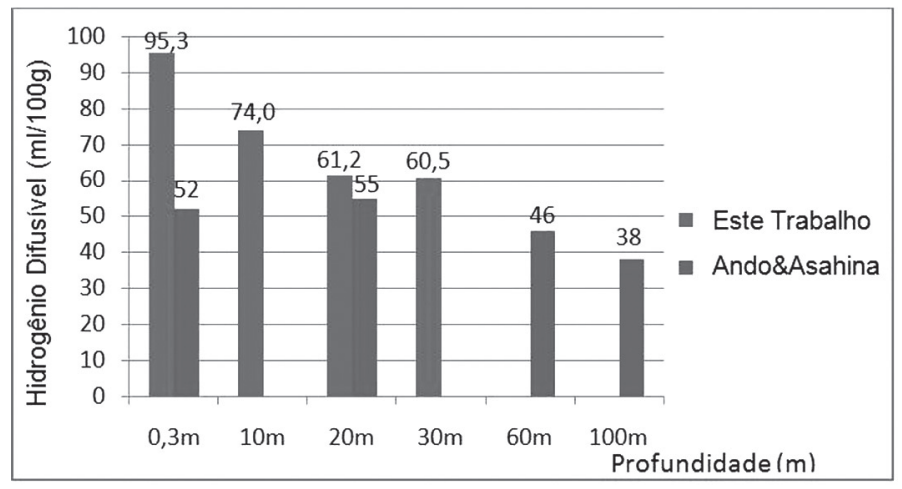

Figura 8. Variação do hidrogênio difusível do metal de solda depositado com a profundidade obtidos neste trabalho e por

Ando\&Asahina (1983)[10] para eletrodos rutílicos

O hidrogênio residual também foi medido e os resultados estão mostrados na Figura 9. Como pode ser observado, não se constatou alterações significativas no hidrogênio residual das soldas molhadas com a variação da profundidade. Pope e Liu (1996) [14] observaram que a adição de hematita no revestimento não altera de forma significativa o hidrogênio residual das soldas molhadas. Os mesmos observaram que o hidrogênio residual tende a um valor de saturação de $5 \mathrm{ml} / 100 \mathrm{~g}$, paralelamente a saturação de oxigênio pelo metal de solda. Assim, como o hidrogênio residual se encontra na estrutura cristalina na forma molecular, geralmente associado a alguma inclusão não-metálica, é razoável que o hidrogênio residual não seja influenciado pela pressão hidrostática, pois em soldas molhadas os níveis de hidrogênio residual estaria atingindo um certo patamar de saturação no que tange a capacidade da estrutura cristalina em absorver as moléculas de hidrogênio.

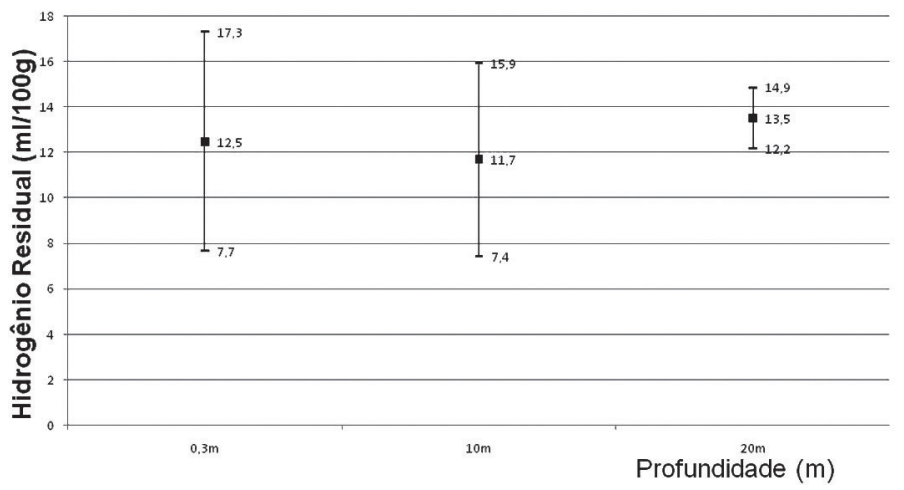

Figura 9. Variação do hidrogênio residual das soldas molhadas com a profundidade

Na Figura 10 é mostrado o gráfico do hidrogênio total, difusível e residual das soldas molhadas em função da profundidade. O hidrogênio total foi calculado como a soma do hidrogênio difusível com o hidrogênio residual. Este gráfico permite observar claramente o comportamento do hidrogênio difusível e residual com a profundidade para o eletrodo revestido E6013. À medida que se aumenta a pressão hidrostática, o hidrogênio difusível diminui e o hidrogênio residual permanece, aproximadamente, constante. Estes resultados estão em consonância com os resultados obtidos por Gooch (1983) [15] em profundidade inferior a $0,5 \mathrm{~m}$.

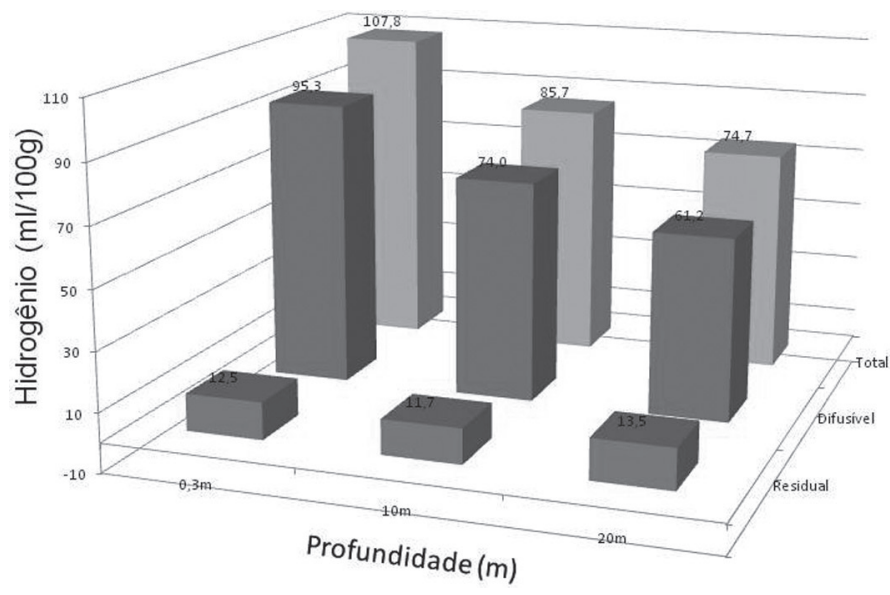

Figura 10. Influência da profundidade no hidrogênio total das soldas molhadas. 
A porosidade do metal de solda foi medida nas diversas profundidades testadas, seguindo-se a metodologia reportada anteriormente. Os resultados podem ser visualizados na Figura 11, onde é possível observar que a porosidade do metal de solda aumentou com a profundidade. $\mathrm{O}$ aparecimento de poros começou a ocorrer no metal de solda a partir da profundidade de $10 \mathrm{~m}$. Variando-se a pressão de $10 \mathrm{~m}$ para $20 \mathrm{~m}$ e, em seqüência, de $20 \mathrm{~m}$ para $30 \mathrm{~m}$, observou-se que a porosidade aumentou de forma substancial. Estes resultados estão em consonância com a literatura $[16,17]$.

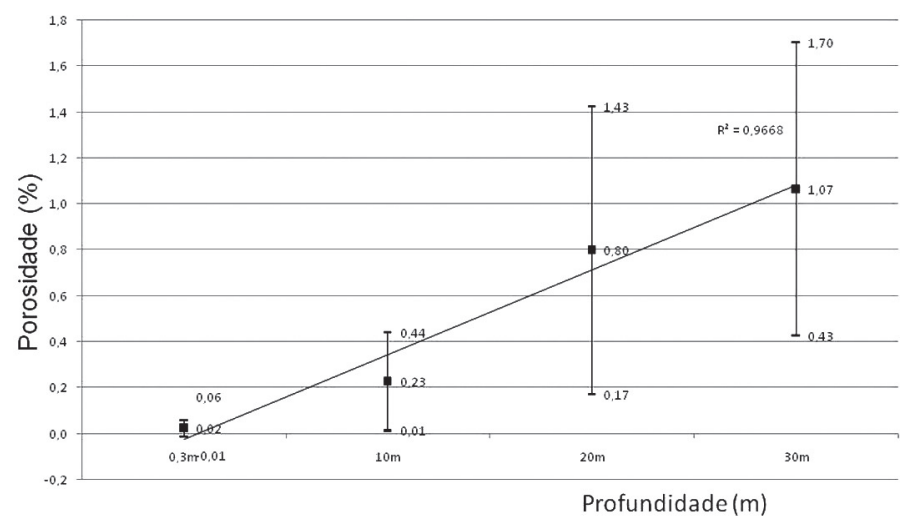

Figura 11. Variação da porosidade do metal de solda com a profundidade

Os parâmetros $\mathrm{P} / \mathrm{L}$ e $\mathrm{R} / \mathrm{L}$ foram calculados. $\mathrm{P} / \mathrm{L}$ é a razão da penetração pela largura do cordão de solda e $R / L$ é a razão do reforço pela largura do cordão de solda. Os resultados das relações P/L e R/L estão sumarizados nas Figuras 12 e13, respectivamente. É possível observar que houve reduções significativas nas relações $\mathrm{P} / \mathrm{L}$ e $\mathrm{R} / \mathrm{L}$ quando a profundidade aumentou de $0,3 \mathrm{~m}$ para $10 \mathrm{~m}$. Para variações de profundidade de $10 \mathrm{~m}$ para $20 \mathrm{~m}$ e $20 \mathrm{~m}$ para $30 \mathrm{~m}$ não ocorreram alterações significativas nas relações $\mathrm{P} / \mathrm{L}$ e R/L.

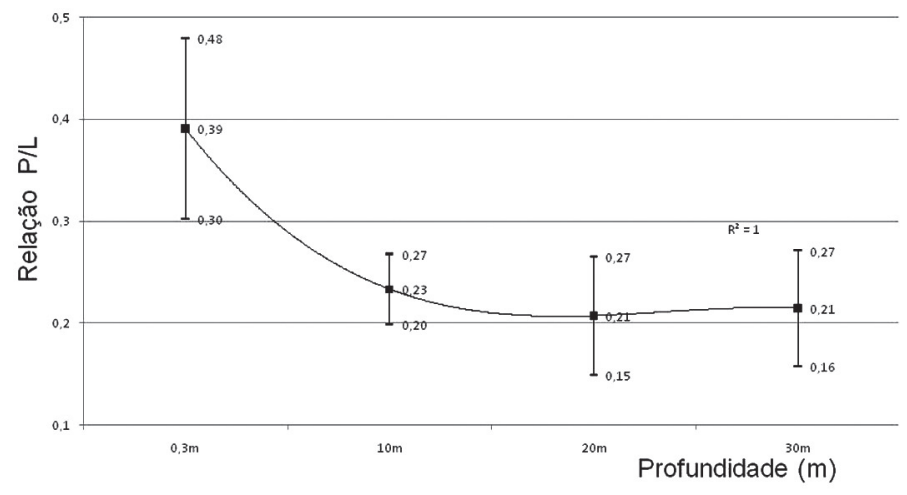

Figura 12. Razão P/L (Penetração/Largura)

As forças na poça de fusão líquida, tais como convecção de Marangoni, força gravitacional, tensão superficial e força de Lorentz podem causar mudanças na morfologia do cordão de solda [18]. Todavia, as alterações na morfologia do cordão que

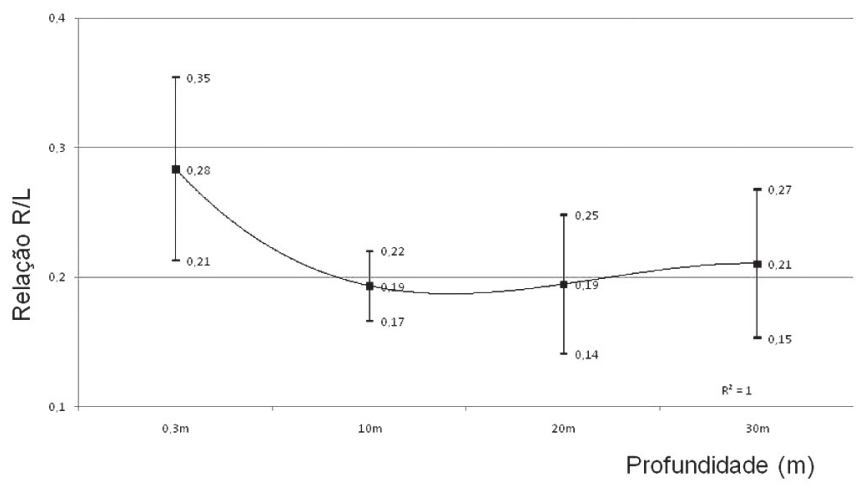

Figura 13. Razão R/L (Reforço/Largura)

foram observadas neste trabalho não se devem primordialmente a tais forças (convecção de Marangoni, força gravitacional, tensão superficial e força de Lorentz). As alterações na morfologia do cordão de solda com o aumento da profundidade de 0,3 para $10 \mathrm{~m}$ pode estar relacionado com a melhoria na estabilidade do arco elétrico em profundidades maiores do que 5,0 metros [ 15 e 16]. Em profundidades até 5 metros o arco fica mais instável apresentando maiores valores de tensão e cordões mais estreitos e irregulares. Em profundidades acima de 5 metros, a pressão do ambiente tende a constringir o arco. Contudo, aparentemente, a base do mesmo permanece com a mesma largura e a melhor estabilidade tende a produzir cordões mais regulares e com maior largura.

\section{Conclusões}

A partir do estudo do efeito da profundidade de soldagem no hidrogênio difusível em soldas molhadas, as seguintes conclusões foram obtidas:

1. O teor hidrogênio difusível reduziu significativamente com a profundidade, quando se variou a pressão de hidrostática de $0,3 \mathrm{~m}$ para $30 \mathrm{~m}$. A partir de $20 \mathrm{~m}$, os resultados sugeriram que o teor hidrogênio difusível do metal de solda tende a estabilidade;

2. Em relação ao hidrogênio residual, não se observou alterações substanciais com a profundidade;

3. A porosidade do metal de solda aumentou substancialmente com a profundidade em que foram feitas as soldas molhadas;

4. Não se observou alterações substanciais na aparência superficial dos cordões de solda produzidos na diferentes profundidades $(0,3 \mathrm{~m}, 10 \mathrm{~m}, 20 \mathrm{~m}$ e $30 \mathrm{~m})$.

5. Com relação à análise dos sinais de tensão, constatou-se uma tendência na redução da tensão média com a profundidade, sendo notória a ocorrência de curtos-circuitos a partir da profundidade de $10 \mathrm{~m}$.

6. Com relação à morfologia do cordão de solda, observouse uma tendência de redução nos parâmetros P/L (razão penetração pela largura do cordão de solda) e R/L (razão reforço pela largura do cordão de solda) quando se variou a profundidade de soldagem de $0,3 \mathrm{~m}$ para $10 \mathrm{~m}$. Contudo, não 
foram observadas alterações significativas nos parâmetros $\mathrm{P} / \mathrm{L}$ e R/L variando-se a profundidade de $10 \mathrm{~m}$ para $20 \mathrm{~m}$ e de $20 \mathrm{~m}$ para $30 \mathrm{~m}$.

\section{Agradecimentos}

$\mathrm{O}$ primeiro autor deste trabalho agradece ao CNPq pela bolsa de mestrado concedida em apoio ao trabalho de mestrado desenvolvido pelo mesmo e ao programa de pós-graduação do departamento de Engenharia Mecânica da UFMG e a ESAB - Brasil. Os autores também agradecem a FAPEMIG pelos auxílios concedidos.

\section{Referências Bibliográficas}

[1] BAILEY N., COE F. R., GOOCH T. G., HART P. H. M., JENKINS N., PARGETER R. J., "Welding Steels Without Hydrogen Cracking", Second Edition, Ed. Woodhead Publishing Ltda, EUA, 1993.

[2] KOU S., "Welding Metallurgy", Ed. John Wiley \& Sons, Hoboken, New Jersey, EUA, 2002.

[3] TROIANO, A. R., "Trans. ASM", 52: 54, 1960.

[4] PETCH H. J., "Nature”, 169: 842, 1952.

[5] BEACHEM C. D., "Metal. Trans.”, 3: 437, 1972.

[6] SAVAGE W. F., Nippes, E. F., and Szekeres, E. S., Weld. J., 55: 276 s, 1976.

[7] GEDEON S. A. E EAGAR T.W., Weld. J., 69: 213s, 1990.

[8] ROWE M. e LIU S., "Recent Developments in Underwater Wet Welding", Science and Technology of Welding and Joining, Vol. 6, No 6, 2001.

[9] BAILEY, N.; COE, F.R.; GOOCH, T.G.; HART, P.H.M.; JENKINS, N.; PARGETER, R.J. "Welding Steels Without Hydrogen Cracking", Woodhead, England, 1973;

[10] ANDO S. e ASAHINA T., "A Study on the Metallurgical Properties of Steel Welds with Underwater Gravity Welding, Underwater Welding", IIW Conference Pergamun Press, p.255261, Trondeheim, 1983.

[11] AMERICAN SOCIETY FOR TESTING AND MATERIALS E260-96. "Standard Practice for Packed Column Gas Chromathography”, EUA, 2003.

[12] PINTO, L., C. M. "Quanticov: um Analisador Microestrutural para Ambiente Windows". Tese de Doutorado. USP/IPEN.Brasil, 1996.

[13] IBARRA, S., GRUPPS, C. E., LIU, S. "State-of-the-Art and Practice of Underwater Wet Welding of

Steel". Proceedings: International Workshop on Underwater Welding of Marine Structures. New Orleans, Lousiana.pp 4967, 1994.

[14] POPE, A.M. AND LIU, S. "Hydrogen Content of Underwater Wet Welds Deposited By Rutile And Oxidizing Electrodes", OMAE, Materials Engineering, Volume III, 1996.

[15] GOOCH, T.G. "Properties of Underwater Wels. Part 1", Procedures Trials, Metal Construction. Pp.164-167, vol.8, March, England, 1983.

[16] PESSOA, E.C.P. "Estudo da Variação da Porosidade ao
Longo do Cordão em Soldas Subaquáticas Molhadas", Tese de doutorado, Universidade Federal de Minas Gerais, Belo Horizonte, Brasil, 2007.

[17] SUGA Y., HASUI, A, "On Formation of Porosity in Underwater Weld Metal", Transactions of the Japan Welding Society, Vol. 17, No. 1, 1986.

[18] HEIPLE, C. and ROPER, J. "Mechanism for Minor Element Effect on Gta Fusion Zone Geometry", Welding Journal, pp. 97102, vol.61, n.4, 1982. 